\title{
Organoid technology and applications in cancer research
}

\author{
Hanxiao Xu' ${ }^{1}$, Xiaodong Lyu ${ }^{2}$, Ming $\mathrm{Yi}^{1}$, Weiheng Zhao ${ }^{1}$, Yongping Song ${ }^{3}$ and Kongming $\mathrm{Wu}^{1^{*}}$ (D)
}

\begin{abstract}
During the past decade, the three-dimensional organoid technology has sprung up and become more and more popular among researchers. Organoids are the miniatures of in vivo tissues and organs, and faithfully recapitulate the architectures and distinctive functions of a specific organ.

These amazing three-dimensional constructs represent a promising, near-physiological model for human cancers, and tremendously support diverse potential applications in cancer research. Up to now, highly efficient establishment of organoids can be achieved from both normal and malignant tissues of patients. Using this bioengineered platform, the links of infection-cancer progression and mutation-carcinogenesis are feasible to be modeled. Another potential application is that organoid technology facilitates drug testing and guides personalized therapy. Although organoids still fail to model immune system accurately, co-cultures of organoids and lymphocytes have been reported in several studies, bringing hope for further application of this technology in immunotherapy. In addition, the potential value in regeneration medicine might be another paramount branch of organoid technology, which might refine current transplantation therapy through the replacement of irreversibly progressively diseased organs with isogenic healthy organoids.

In conclusion, organoids represent an excellent preclinical model for human tumors, promoting the translation from basic cancer research to clinical practice. In this review, we outline organoid technology and summarize its applications in cancer research.
\end{abstract}

Keywords: Organoid, Cancer, Drug development, Drug efficacy, Drug toxicity, Personalized medicine, Immunotherapy, Regeneration medicine

\section{Background}

During the past decades, enormous efforts have been exerted to cancer research $[1,2]$ and substantial progresses have been achieved in diagnosis $[3,4]$ and treatment [5-12]. However, cancer still represents a major worldwide health concern and many obstacles remain to be solved for further improving life quality and prolonging survival of cancer patients. The development of effective treatment regimens is among the major hurdles. Due to poor recapitulation of human tumors by conventional cancer models, numerous drugs working in these cancer models are finally eliminated in clinical trials because of either ineffectiveness or unbearable side effects.

\footnotetext{
* Correspondence: kmwu@tjh.tjmu.edu.cn

${ }^{1}$ Department of Oncology, Tongji Hospital of Tongji Medical College, Huazhong University of Science and Technology, 1095 Jiefang Avenue, Wuhan 430030, Hubei, China

Full list of author information is available at the end of the article
}

Traditional two-dimensional (2D) cell line cultures and patient-derived tumor xenografts (PDTXs) have long been employed as tumor models and have made tremendous contribution to cancer research. However, many drawbacks hamper these two models for clinical use. 2D cell line cultures show their inability in simulating some vital subjects, such as the immune system, microenvironment, stromal compartments, and organspecific functions. Other limitations include the lack of genetic heterogeneity of original tumors after many passages for cancer cell lines [13] as well as experiencing mouse-specific tumor evolution [14] and being consuming in money, time, and resources for PDTXs [15].

Organoid technology springs up and becomes an independent research tool. Organoids are three-dimensional (3D) constructs and can be developed from embryonic stem cells (ESCs), induced pluripotent stem cells (iPSCs), somatic SCs, and cancer cells in specific 3D culture

(c) The Author(s). 2018 Open Access This article is distributed under the terms of the Creative Commons Attribution 4.0 International License (http://creativecommons.org/licenses/by/4.0/), which permits unrestricted use, distribution, and 
system (Fig. 1). Stem cells are a class of under-differentiated cells with self-renewing capacity and the potential to regenerate various tissues and organs. According to the developmental stage in which stem cells are located, they are divided into embryonic stem cells and adult stem cells. Embryonic stem cells are a type of cells isolated from early embryos with the ability of unlimited proliferation, self-renewal, and multi-directional differentiation. Progenitor cells belong to adult stem cells and are undifferentiated pluripotent or multipotent stem cells. Progenitor cells are present in various adult tissues of organisms and are responsible for the repair and regeneration process after tissue damage.

These amazing 3D tissues in small scale are fabricated in the laboratory and resemble the parent organ in vivo in terms of structure and function. Three basic features are as follows: firstly, it contains multiple cell types of the in vivo counterpart; secondly, the cells organize similarly to the primary tissue; thirdly, it functions specifically to the parent organ [16]. This powerful technology bridges the conventional $2 \mathrm{D}$ in vitro models and in vivo models, and exerts great potential for clinical applications (Fig. 2), especially in cancer research [17]. Tumor modeling might be a pivotal branch of organoid technology [18, 19], including modeling infection-cancer development [20, 21], mutation-tumorigenesis processes $[22,23]$ and genetic carcinoma $[24,25]$. Apart from cancer modeling, organoid technology also exerts enormous potential in evaluation of efficacy and toxicity of drugs [26],

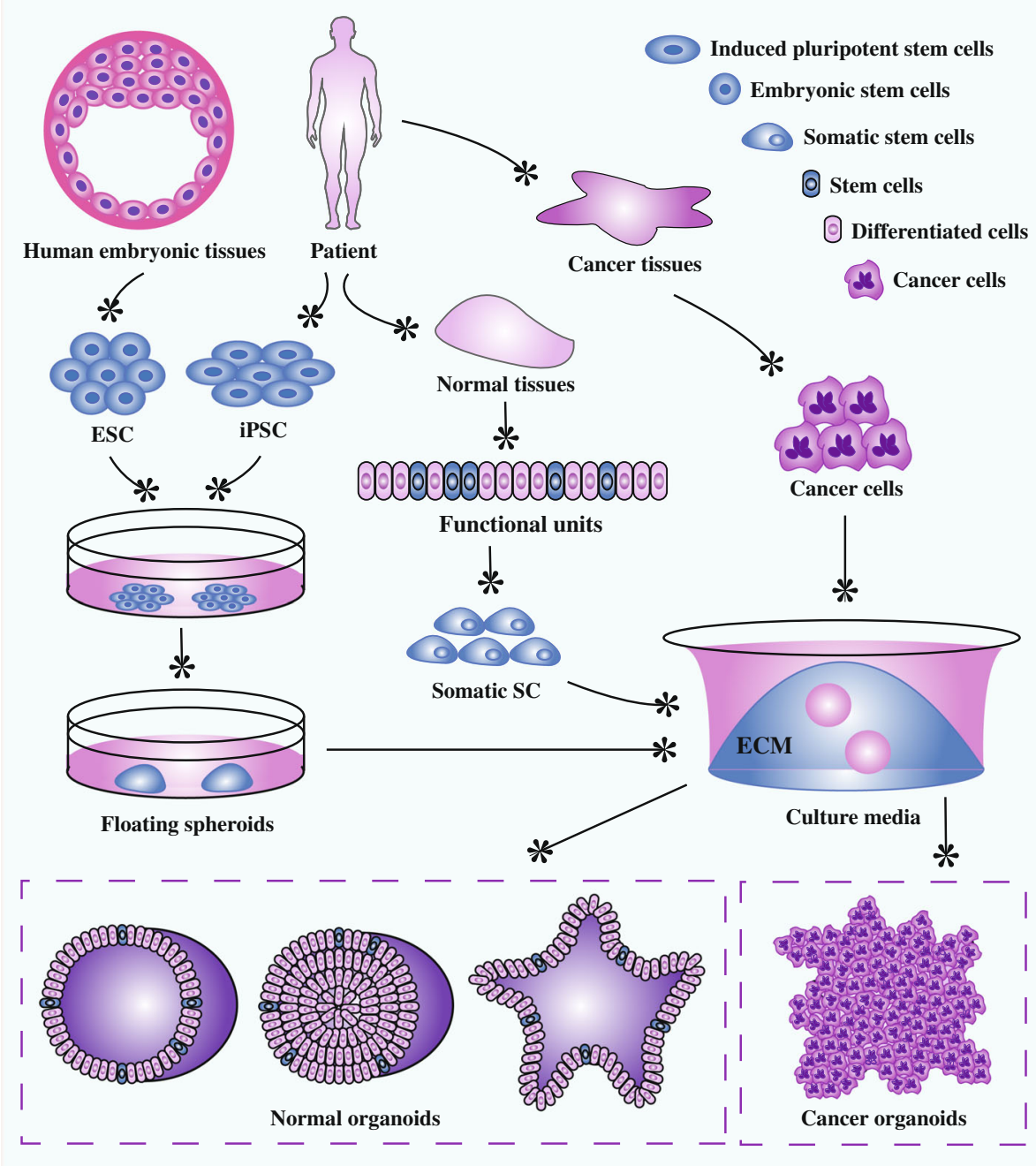

Fig. 1 Organoid establishment from stem cells and cancer cells. Embryonic stem cells from human embryonic tissues and induced pluripotent stem cells from adult tissues firstly experience directed differentiation, generate floating spheroids, and subsequently are planted on extracellular matrix in specific culture medium to initiate organoid culture. Primary tissues from patients can be dissociated into functional units, which contain somatic stem cells. These somatic stem cells are enriched and cultured in three-dimensional medium to form organoids. Tumor cells isolated from cancer tissues can also form tumoroids in well-defined three-dimensional culture 


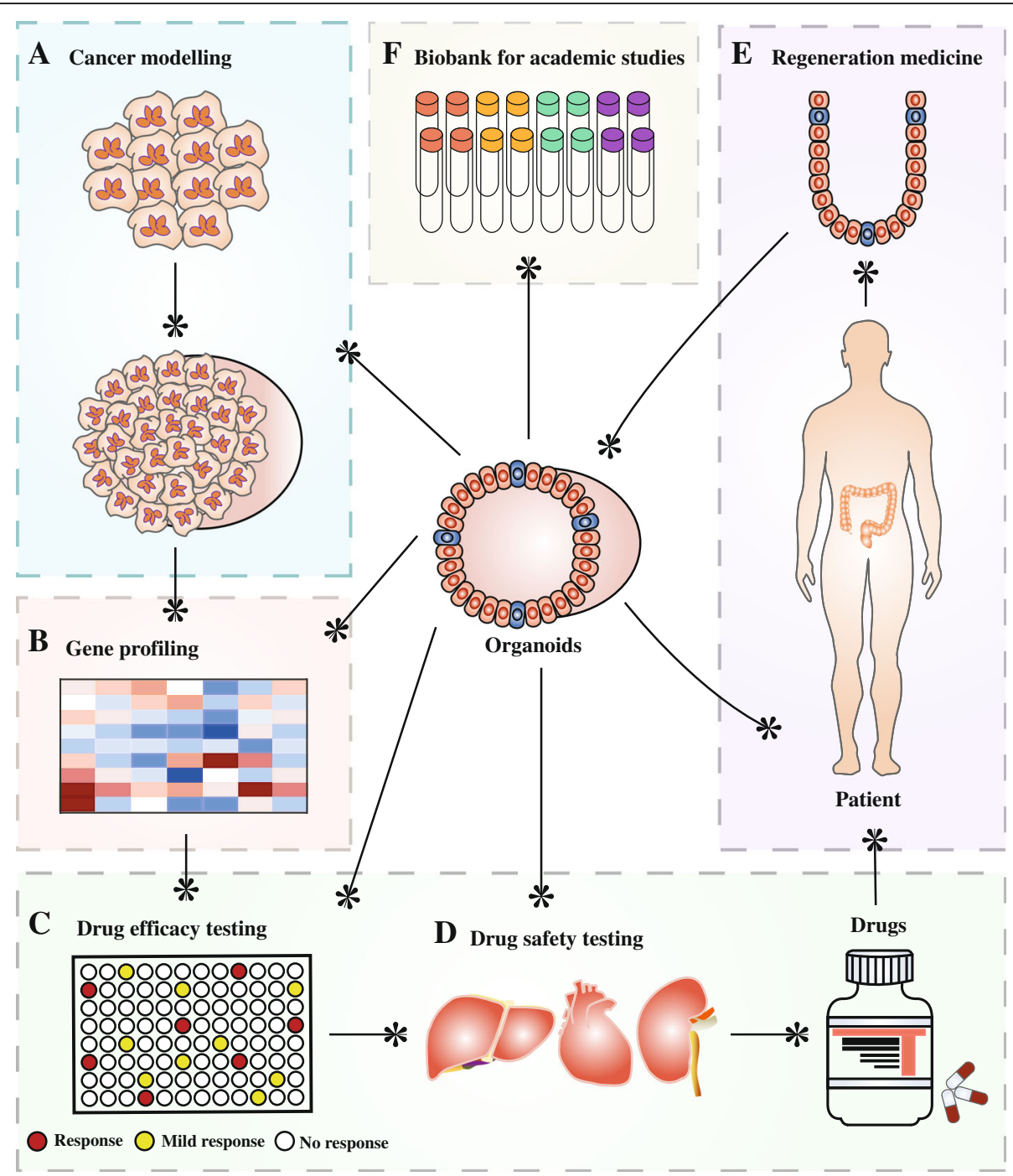

Fig. 2 Potential applications of organoids in tumor modeling, drug development, and regeneration medicine. Organoid technology can be exploited to model human cancers (a), and gene-profiling analyses (b) of tumoroids and corresponding healthy organoids promote the identification of novel targeted therapies. Organoids can also promote the development of anti-tumor drugs, including efficacy testing (c) and toxicity testing (d). In addition, organoids can be a potential candidate in regeneration medicine for the replacement of irreversibly progressively diseased organs with healthy organoids (e). Besides, organoids can also be cryopreserved for academic studies (f)

regeneration medicine $[27,28]$, and precision treatment $[29,30]$. Until quite recently, organoids have been established successfully for multiple cancer types, including stomach cancer [26], colorectal cancer [3133], liver cancer [34], pancreatic cancer [35, 36], prostate cancer [37], and breast cancer [38].

In this review, we outline a brief history of organoids, describe organoids of diverse cancer types, focus on the potential applications of this promising technology in oncology, and finally discuss the current limitations.

\section{The history of organoids}

The notion that mammalian cells are inherently endowed with self-organizing capacity has long been widely known among researchers, and this ability has been employed to develop 3D cultures from primary tissues. Numerous types of culture systems have been reported in early studies [39-42], but no methods could achieve long-term culture and maintain the basic crypt-villus physiology. Encouragingly, the year 2009 witnessed the advancement of intestinal organoid culture system, a chief technological breakthrough in the SC field [43]. The novel culture system contained laminin-rich Matrigel replacing extracellular matrix (ECM) and growth factors including epidermal growth factor (EGF), Noggin, Wnt, and R-spondin. 3D mouse crypt structures in which continuously renewing epithelial layer exhausted apoptotic cells into a central lumen lined by crypt-like and villus-like sections were 
established in this 3D culture system, and these features remained when cultured for 8 months [43]. Subsequently, this culture system was adapted for the establishment of human intestinal organoids and other organ 3D architectures, such as the liver, stomach, and colon [44-46]. The organoid technology has become widely accepted in recent years, since these 3D cultures faithfully recapitulate the genotype, phenotype, and cellular behaviors of parent tissues [47].

Breast organoid cultures also experience a gradual evolution from the earliest attempts of in vitro cultivation of organ explants to the current relatively refined versions [48-50]. Mammary gland explants of from virgin mice could be cultivated in a serum-free medium, which consists of four major components: aldosterone, prolactin, insulin, and cortisol [48]. Through testing the mammaryderived growth inhibitor (MDGI) in mammary explants in vitro from mice at different development stages, it was demonstrated that MDGI expression was correlated with functional differentiation of normal mammary gland [48]. Next, mouse mammary gland cultivated in organ culture containing MRG protein showed a differentiated morphology with the upregulation of beta-casein [49]. Recently, it has been indicated that 3D cultures of breast cancer could more accurately model the structural and functional changes during the conversion from breast ductal carcinoma in situ to invasive carcinoma [50]. Up to now, breast cancer organoids have been efficiently established for studying breast cancer biology, and efforts are still in need for further improving culture conditions in order to overcome the current limitations.

Early in the 1980s, organotypic cultures have been employed to cultivate embryonic kidney, which allowed accurate manipulation of diversity developmental events in vivo in comparison with monolayer cell cultures [51]. However, the in vitro conditions led to metabolic changes, and it was difficult to realize long-term cultures because of the nutrition insufficiency-induced tissue damage [51]. When fetal murine metanephric tissues were isolated and incubated in serum-free medium, organotypic proximal tubular and glomerular epithelial differentiation were observed but without perfusion, urine production, and vascularization [52]. Quite recently, it was reported that host-derived vascularization formed in iPSC-derived kidney organoids in fully defined conditions without any exogenous vascular endothelial growth factor [53]. Progressive morphogenesis, including functional glomerular perfusion in function as well as connection to pre-existing vascular system, glomerular basement membrane, and fenestrated endothelial cells in structure, was observed in these organoids after transplanted under the kidney capsule [53].

Isolated brain cells, cultured in serum-free medium with classical hormones, EGF, fibroblast growth factor
(FGF), attachment factors/basal membrane components, transport proteins, transferrin, albumin, vitamins, experienced morphological, bioelectrical, and biochemical differentiation [54-56]. During the past a few years, a variety of neural organoids have been established from ESCs or iPSCs in refined 3D culture systems which faithfully manipulated brain structures and some specific functions, including the whole brain [57] and sub-brain regions, such as hypothalamus [58], adenohypophysis [59], midbrain [60], cerebellum [61], and hippocampus [62].

\section{Establishment of cancer organoids}

The poverty of in vitro tumor models that mimic the heterogenicity of human cancers has impeded the full understanding on tumor pathogenesis, therapeutic responses, and adverse reactions. The 3D organoid system draws researchers' attention and has tremendous potential for modeling human cancers [63-65]. Major establishment procedures for each cancer organoid type were showed in Fig. 3. 3D culture system for organoid establishment consists of Matrigel or basement membrane extract as ECM substitutes and specific culture medium. Components in organoid culture medium majorly include advanced Dulbecco's modified Eagle's medium (ADMEM)/F12, penicillin/streptomycin, primocin, GlutaMAX, HEPES, B27, N2, EGF, FGF10, FGF7, hepatocyte growth factor (HGF), Wnt3A, Noggin, R-spondin-1, gastrin, prostaglandin $E_{2}$, nicotinamide, neuregulin 1, N-acetylcysteine, Y27632 (a Rho kinase inhibitor), A-8301 (a transforming growth factor-beta inhibitor), and SB202190 (a p38 inhibitor) (Table 1). There are minor differences in medium components among different tumoroid types [26, 34, 38, 66-68], shown in Table 2. Compared with conventional 2D cultures of cell lines, the most outstanding feature is the addition of ECM substitutes in 3D cultures.

\section{Stomach cancer}

Organoid technology has been applied to model gastric cancer $[26,69]$. There are some subtle differences among studies in detailed manipulation. The proliferation rates of gastric cancer organoids were significantly higher than normal controls in vitro, and tumor growth of organoid engrafts in vivo was consistent with the expansion rates of corresponding organoids in vitro [69]. The organoids faithfully recapitulated important characteristics of the corresponding parent tumors as exemplified by architectures, the expression of typical gastric cancer markers including carcinoembryonal antigen, cadherin 17, cytokeratin 7 (KRT7), and periodic acid Schiff reaction [69]. These organoids harbored diverse mutations, which were prevalent in gastric cancer and could be detected in corresponding 

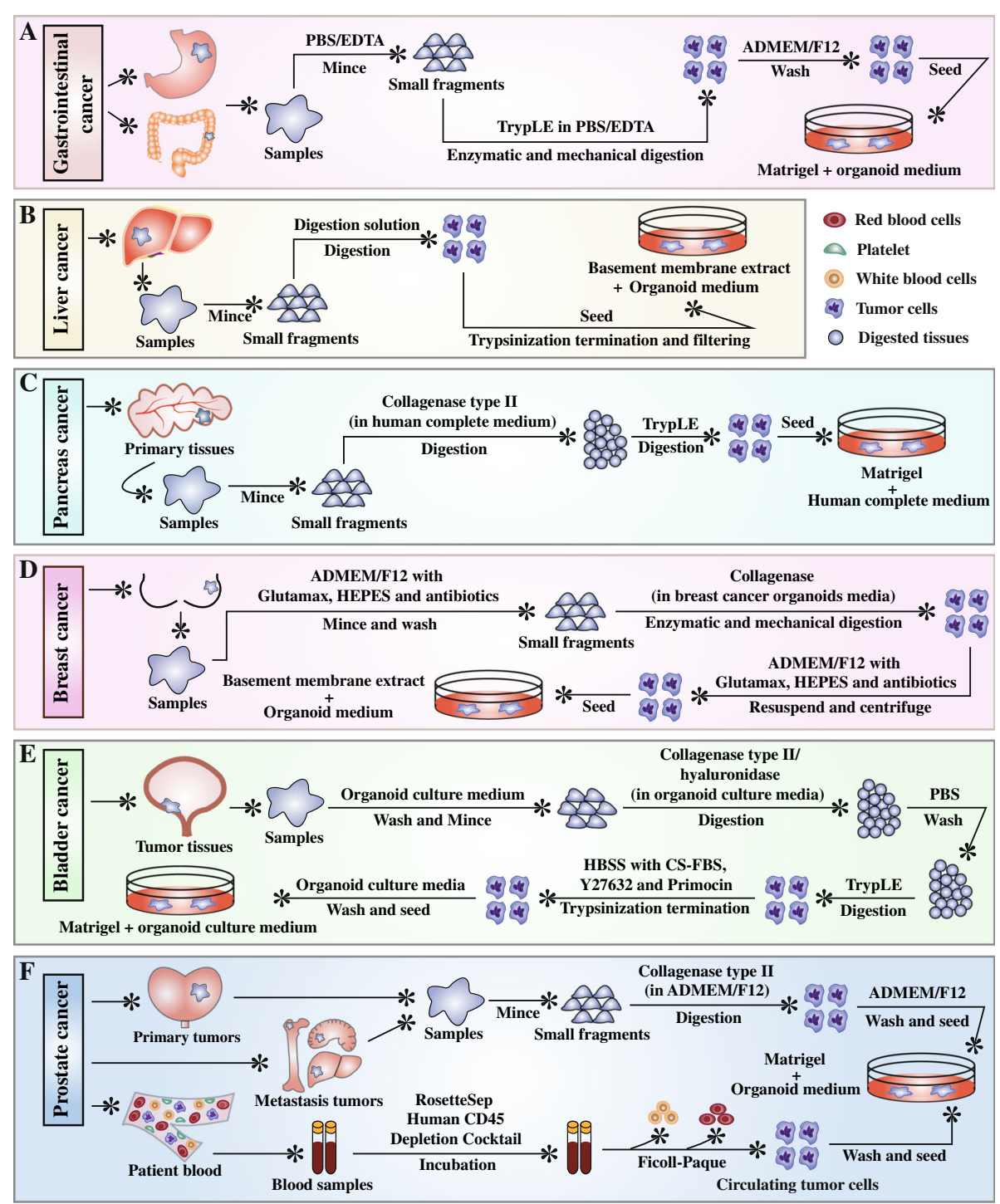

Fig. 3 Flow charts for tumoroid establishment processes. Major steps during tumoroid establishment of gastrointestinal cancer (a), liver cancer $(\mathbf{b})$, pancreatic cancer $(\mathbf{c})$, breast cancer $(\mathbf{d})$, bladder cancer $(\mathbf{e})$, and prostate cancer $(\mathbf{f})$ are shown

primary tumors, such as mutations in mutL homolog 1, mutS homologs 6, phosphatidylinositol 3-kinase catalytic subunit, ERBB2, and TP53 [69].

\section{Intestinal cancer}

Intestinal cancer organoids have been successfully developed in several studies [26, 31-33]. Sato T and colleagues demonstrated that colorectal cancer organoids responded diversely to Wnt3A/R-spondin-1, oxygen concentration, and SB202190 in organoid proliferation in consideration of the phenomenon that some tumoroids needed Wnt activators, some required hypoxia, and some showed growth suppression in reaction to SB212090 exposure [31]. Colorectal cancer organoids have been successfully propagated from different anatomical sites (right-sided, left-sided, and rectal tumors) and rare histological subtypes (mucinous adenocarcinoma and neuroendocrine carcinoma) [31]. Colorectal cancer organoids showed remarkable resemblance with the primary tumors in the aspects of histological subtypes, differentiation hierarchies, mutational landscape, and transcriptomic profiling $[26,31]$. It was noted that colorectal cancer organoids in combination with an orthotopic transplantation system could more accurately model tumor formation and liver metastasis in the native colon environment [70]. Proteomic analyses on colorectal cancer organoids showed each organoid from distinct patients harbored different proteomic profiles, 
Table 1 Growth factors and small molecule inhibitors applied in organoid cultures

\begin{tabular}{|c|c|}
\hline & Function \\
\hline \multicolumn{2}{|l|}{ Growth factors } \\
\hline EGF & $\begin{array}{l}\text { - A well-known growth factor for epithelial tissues; } \\
\text { - EGF, binding to EGF receptors, induces hyperplasic changes; } \\
\text { - EGF promotes tumor growth through stimulating the proliferation of cancer cells. }\end{array}$ \\
\hline FGF10 & $\begin{array}{l}\text { - FGF10/FGF receptor 2lllb axis is important for the organ development, including the stomach, liver, breast, and prostate; } \\
\text { - FGF10 promotes migration and invasion of pancreatic cancer cells and drives tumorigenesis of breast cancer; }\end{array}$ \\
\hline FGF7 & - FGF7/FGF receptor 2 signaling promotes growth, invasion, and migration of tumors. \\
\hline HGF & - HGF/Met signaling promoted oncogenesis, tumor angiogenesis, tumor invasion of multiple tumor types; \\
\hline Wnt & $\begin{array}{l}\text { - A master regulator in regulation of cell development, proliferation, differentiation, adhesion, and polarity; } \\
\text { - The aberrant activation of Wnt signaling promotes carcinogenesis and progression of cancers. }\end{array}$ \\
\hline Noggin & $\begin{array}{l}\text { - An inhibitor of bone morphogenetic proteins that modulates cellular differentiation, proliferation, and apoptosis; } \\
\text { - Noggin promotes bone metastasis of some cancers and is associated with tumorigenesis of primary bone malignancies. }\end{array}$ \\
\hline R-spondin-1 & $\begin{array}{l}\text { - The ligand of Lgr5 and a niche factor that is required for the self-renewal of stem cells and activates Wnt signaling; } \\
\text { - R-spondin-1facilitates the growth and metastasis of cancer cells. }\end{array}$ \\
\hline Gastrin & - Gastrin stimulates tumor growth through promoting the proliferation and suppressing the apoptosis of cancer cells; \\
\hline Prostaglandin $\mathrm{E}_{2}$ & - Prostaglandin $\mathrm{E}_{2}$ promotes angiogenesis in gastric cancer through the up-regulation of vascular endothelial growth factor. \\
\hline Nicotinamide & - Vitamin PP is a nutrient that is required for long-term culture of organoids. \\
\hline Neuregulin 1 & $\begin{array}{l}\text { - It is a ligand of human EGF receptor tyrosine kinases-3 and -4; } \\
\text { - It is involved in mammary development and tumorigenesis. }\end{array}$ \\
\hline \multicolumn{2}{|l|}{ Molecule inhibitors } \\
\hline Y27632 & $\begin{array}{l}\text { - A Rho kinase inhibitor that effectively reduces the anoikis of dissociated stem cells; } \\
\text { - Y27632 improves culture media and promotes proliferation of tumor epithelial cells for long-term in vitro; }\end{array}$ \\
\hline A-83-01 & $\begin{array}{l}\text { - A transforming growth factor-beta inhibitor; } \\
\text { - Transforming growth factor-beta inhibitor suppresses the proliferation of organoids; }\end{array}$ \\
\hline SB202190 & $\begin{array}{l}\text { - It is a p38 inhibitor and suppresses the proliferation and migration of cancer cells; } \\
\text { - High concentration of SB202190 contributes to relatively lower efficiency of the establishment of breast tumoroids. }\end{array}$ \\
\hline
\end{tabular}

which signifies that specific organoid proteome profile from patients can guide precision management [71].

\section{Liver cancer}

Human liver cancer organoids have been established in several studies [72]. Primary liver cancer organoids of three major types including hepatocellular carcinoma (HCC), cholangiocarcinoma (CC), and combined hepatocellular$\mathrm{CC}(\mathrm{CHC})$ have been successfully developed in specific isolated medium and passaged in expansion medium [34]. Specific isolated medium used during the establishment of liver cancer organoids includes two types: classical human liver organoid isolation medium and tumoroid-specific isolation medium [34]. Some organoids needed tumoroid-specific isolation medium, while some other organoids required classical isolation medium [34]. It was observed that one $\mathrm{CC}$ organoid only grew in classical human liver organoid isolation medium due to the need of R-spondin-1 for growth [34]. Y27632 is only required during the first 23 weeks of culture. At histological level, these primary liver cancer organoids recapitulated their parent tumors to a great degree even after long-term expansion [34]. The organoids of $\mathrm{HCC}$ and $\mathrm{CHC}$ were solid architectures filled with HCCs, in which a histological characteristic of HCC (pseudoglandular rosettes) was observed [34]. Just as found in patients' tissues, it was also noted that CC tumoroids contained a great many glandular regions with cancer cells, which invaded the lumen and grew in a cribriform manner [34]. For expression profile, alfa-fetoprotein and glypican-3, markers of HCC, were upregulated in HCC tumoroids but the levels of CC markers remained low [34]. Conversely, CC markers (epithelial cell adhesion molecules, KRT19, and S100 Calcium Binding Protein A11 were enhanced in CC organoids but HCC markers were remarkably downregulated [34]. For transcriptional level, these organoids faithfully recapitulated transcriptomic alterations, which were identified in corresponding original tissues [34].

\section{Pancreatic cancer}

Pancreatic tumor organoids have been successfully established in a flurry of studies [36, 66, 73]. For long-term maintenance and enrichment of KRAS-mutant pancreatic ductal adenocarcinoma (PDAC) organoids, serum and EGF were eliminated from the culture medium [36]. For the organoids that were sensitive to the removal of EGF, an inhibitor of murine double minute 2 Nutlin3 or Noggin elimination could be employed to select possible existing organoids with TP53 or SMAD4-mutants, respectively 
Table 2 Culture systems of multiple tumoroids

\begin{tabular}{|c|c|c|c|c|}
\hline \multirow[t]{2}{*}{ Tumoroid type } & \multicolumn{3}{|l|}{ Culture components } & \multirow[t]{2}{*}{ Ref } \\
\hline & Extracellular matrix & Growth factors & Molecule inhibitors & \\
\hline Stomach cancer & Matrigel & \multirow{2}{*}{$\begin{array}{l}\text { ADMEM/F12, penicillin/streptomycin, L-glutamine, B27, N2, } \\
\text { bovine serum albumin, EGF, Noggin, R-spondin-1, gastrin, } \\
\text { FGF10, FGF-basic, Wnt3A, prostaglandin } E_{2} \text {, and nicotinamide }\end{array}$} & \multirow{2}{*}{$\begin{array}{l}\text { A-83-01 } \\
\text { Y27632 } \\
\text { SB202190 }\end{array}$} & \multirow[t]{2}{*}{ [26] } \\
\hline Intestinal cancer & (growth factor reduced) & & & \\
\hline Liver cancer & Basement membrane extract & $\begin{array}{l}\text { Classical human liver organoid isolation medium: } \\
\text { ADMEM/F12, penicillin/streptomycin, GlutaMAX, HEPES, } \\
\text { B27 (without vitamin A), N2, N-acetylcysteine, nicotinamide, } \\
\text { gastrin 1, EGF, FGF10, HGF, forskolin, R-spondin-1, Wnt3A, } \\
\text { and Noggin } \\
\text { Tumoroid-specific isolation medium: } \\
\text { Classical human liver organoid isolation medium with the } \\
\text { elimination of R-spondin-1, Wnt3A, and Noggin as well as } \\
\text { addition of dexamethasone } \\
\text { Human healthy liver-derived organoids expansion medium } \\
\text { Classical human liver organoid isolation medium with the } \\
\text { elimination of Y27632, Wnt3A, and Noggin }\end{array}$ & $\begin{array}{l}\text { A-83-01 } \\
\text { Y27632 }\end{array}$ & [34] \\
\hline Pancreatic cancer & Matrigel & $\begin{array}{l}\text { ADMEM/F12, penicillin/streptomycin, GlutaMAX, HEPES, B27, } \\
\text { N-acetylcysteine, EGF, R-spondin-1, gastrin 1, Wnt3A, Noggin, } \\
\text { and FGF }\end{array}$ & A-83-01 & [66] \\
\hline Breast cancer & $\begin{array}{l}\text { Basement membrane extract } \\
\text { (reduced growth factor) }\end{array}$ & $\begin{array}{l}\text { ADMEM/F12, penicillin/streptomycin, GlutaMAX, HEPES, B27, } \\
\text { N-acetylcysteine, R-spondin-1, FGF7, FGF10, nicotinamide, } \\
\text { Noggin, primocin, and neuregulin } 1\end{array}$ & $\begin{array}{l}\text { A-83-01 } \\
\text { Y27632 }\end{array}$ & [38] \\
\hline Bladder cancer & Matrigel & Hepatocyte media with EGF, FBS, GlutaMAX, and primocin & Y27632 & [67] \\
\hline Prostate cancer & $\begin{array}{l}\text { Matrigel } \\
\text { (growth factor reduced) }\end{array}$ & $\begin{array}{l}\text { ADMEM, penicillin/streptomycin, primocin, GlutaMAX, B27, EGF, } \\
\text { N-acetylcysteine, FGF10, FGF-basic, nicotinamide, testosterone, } \\
\text { prostaglandin } \mathrm{E}_{2} \text { Noggin, and R-spondin }\end{array}$ & $\begin{array}{l}\text { A-83-01 } \\
\text { SB202190 }\end{array}$ & [68] \\
\hline
\end{tabular}

[36]. Driver-gene alterations including KRAS, cyclin-dependent kinase inhibitor $2 A, T P 53$, and SMAD4, which are common in human pancreatic carcinoma, were detected in corresponding organoids. When transplanted into mice, the organoids formed tumors in vivo like the derived PDAC [36]. Optical metabolic imaging of PDAC organoids is quite sensitive to metabolic changes induced by anti-cancer drugs. The combination of this nondestructive method and cancer organoid platform help better monitoring of dynamic drug response for patients in vitro [74].

\section{Breast cancer}

Breast cancer organoid models have been successfully achieved to study breast carcinoma biology [38, 75, 76]. Hans Clevers, et al. highlighted that (1) neuregulin 1 was an essential element for efficient generation and long-term expansion for breast cancer organoids; (2) Wnt3A was not essential for culture conditions; (3) EGF was a double-edged sword for low concentration impeding proliferation and high concentration leading to organoid sinking and gradual loss of 3D organization; (4) SB202190 at high concentration was detrimental to effective establishment of breast cancer organoids [38]. The breast cancer organoid lines were consistent with the parent tumors in morphology, histopathology, hormone receptor status, human epidermal growth factor receptor 2 (Her2) status, mutational landscape, and DNA CNAs [38]. Organoids represent a valuable tool for evaluating local tumor invasion of breast cancer, which is the basis for distant metastasis and involves the interactions between tumor, ECM, and stromal cells [75].

\section{Bladder cancer}

The culture system of bladder cancer organoids has been reported in many studies [67, 77]. A biobank of patient-derived bladder cancer organoids has been established by Suk Hyung Lee and colleagues, who reported a well-defined culture protocol for propagation of bladder cancer organoids [67]. Histological analysis demonstrated the remarkable similarity between these organoids and the corresponding derived tumors [67]. In terms of the mutational profiles for 468 tumor-related genes, high concordance was observed between bladder cancer organoids and their parental tumors [67]. However, there were some genomic changes in organoids, which accompanied with cancer evolution in culture [67]. According to the deep sequencing analysis, some mutations were lost or gained during the continuous process in organoid cultures [67]. Using bladder tumoroids as a platform, drug response was partly associated with mutational profiles, signifying the feasibility that bladder tumor organoids derived from patients can be employed to predict treatment response and guide personalized therapies for each individual patient [67]. 


\section{Prostate cancer}

Prostate cancer organoids from patients have been reported in multiple studies [37, 68, 78]. Dong Gao's group provided a detailed protocol for the metastatic prostate cancer organoid establishment from metastatic tumor cells and circulating tumor cells [37]. A diversity of characteristic copy number alterations (CNAs) in prostate cancer were detected in the prostate tumoroid lines, including deletions of SHQ1, transmembrane protease, serine 2/erythroblast transformation-specific-related gene and phosphatase and tensin homolog (PTEN) as well as the amplification of androgen receptor (AR) [37]. Furthermore, mutation profile detected in organoid lines overlaid the prevalent mutations in prostate cancer, such as mutations in TP53, forkhead box A1, phosphoinositide-3-kinase regulatory subunit 1 (PIK3R1), alpha thalassemia/ mental retardation syndrome X-linked, checkpoint kinase 2, KDM4C, KDM4D, and MLL2 [37]. When transplanted into severe combined immunodeficient mice, organoid lines displayed histological patterns found in parent tumors [37]. The 3D co-cultures of bone stroma cells and prostate cancer cells not only induced cytogenetic and gene expression changes in stromal cells but also fueled growth and metastasis of prostate tumoroids, which indicated the co-evolution of cancer and stroma as well as the significance of tumor-stroma interaction [79].

\section{Other cancer types}

Organoids of other cancer types have also been faithfully established, such as CC [26], thyroid cancer [80], ovarian cancer (OC) [81], and brain cancer [82]. CC organoids derived from human metastatic $\mathrm{CC}$ biopsies retained rearrangements of fibroblast growth factor receptor 2 that parent tumors harbored [26]. Mouse models of poorly differentiated thyroid tumors has been established through the transplantation of the thyroid organoids with enhanced expression of oncogene neuroblastoma $R A S$ derived from mouse with P53 knockout [80]. In addition, OC cell lines from patients were planted on Matrigel in cancer SC medium containing Gentamicin, Fungizone, and Y27632, and formed organoids with the expression of tumor marker carbohydrate antigen 125 [81]. The infiltration capacity of glioblastoma multiforme cell into healthy brain parenchyma partly accounts for that high-grade of this tumor type cannot benefit much from surgical management [82]. Human glioblastoma multiforme spheroids could spontaneously infiltrate early-stage brain organoids and form hybrid organoids, demonstrating an invasive tumor phenotype and helping explore anti-invasion strategies for this refractory disease [82].

However, organoid models of some cancer types have not been reported as exemplified by lung cancer. Lung normal organoids can be developed from basal cells derived from trachea or large airways or even nasal epithelium, commonly containing $\mathrm{TRP}^{+} 3^{+}$and $\mathrm{KRT}^{+}$ basal cells, secretory goblet cells, and functional multiciliated cells [83, 84]. Through clustered regularly interspersed short palindromic repeats (CRISPR)/ CRISPR-associated protein 9 (Cas9) gene editing technology, organoid can be employed as a platform to identify genes that modulate vital airway functions, such as selective permeability, barrier formation, fluid transport, innate immunity, and ciliogenesis [85, 86]. According to these findings, we can suppose that oncogene-activated mutations introduced by CRISPR/Cas 9 might drive tumorigenesis in primary normal lung organoids. Further efforts are in need for application of organoid technology in lung cancer.

\section{Organoid in cancer modeling}

Some infectious pathogens are identified to be significant risk factors of cancer, such as Helicobacter pylori in gastric cancer, Salmonella enterica in gallbladder carcinoma, hepatitis virus in $\mathrm{HCC}$, and Epstein-Barr virus (EBV) in gastric cancer, nasopharyngeal carcinoma, and lymphoma. However, there is still a lack of extensive understanding of the direct relationships and causal mechanisms between the infectious pathogens and corresponding cancers. Organoids can serve as a potential excellent model for studying these processes through co-culture systems with different pathogens. Neefjes J and colleagues employed co-cultures of murine-derived genetically predisposed gallbladder organoids and Salmonella enterica to explore the epidemiological association between gallbladder carcinoma and Salmonella Typhi infection, and supported that Salmonella enterica triggered and maintained malignant transformation accompanied by TP53 mutations and $c-M y c$ amplification through Salmonella enterica effectors-induced activation of mitogen-activated protein kinase and AKT pathways [20]. Besides, viral infectious organoid models can also be established as exemplified by intestinal organoids with rotavirus infection [21], indicating that the virustumor relationship can also be simulated by co-culture systems, such as hepatitis virus versus liver cancer and EBV versus nasopharyngeal carcinoma. Modeling of the transition from infection to tumor formation and progression of organoids might help to reveal pathogenic mechanisms and find potential anti-tumor targets during this process.

Cancers occur on the genetic basis of sequential accumulation of mutations, signifying that it is pivotal to throw light upon the mutational processes during homeostasis and tumorigenesis. Knowledge of original mutation profile has been demonstrated to be of importance [22], for which healthy organoids provide a platform. Whole genome sequencing on human colon organoids with knockout of DNA repair genes through CRISPA-Cas9 technology 
revealed that the deficiency in mismatch repair genes contributed to mutation accumulation through replication errors, and deficiency in the cancer-predisposition gene DNA glycosylase led to mutation profile previously noted in cancer patients [23]. In addition, understanding of heterogeneous mutational signatures underlying tumor progression is also of great significance, which can also be prompted by organoid technology. Remarkably increased mutation rates and acquisition of new mutational profile were observed during development of colorectal tumoroids, and the diverse contributions of mutational processes in different regions of the same tumor were demonstrated by Roerink SF and colleagues [87]. It is interesting and feasible to employ organoid platform to evaluate the impact of drugs and irradiation on mutation profiles of cancer and normal cells as well as explore the mutational differences between sensitive and resistant organoids towards treatments.

Genetic cancer modeling is another paramount potential application of tumoroids [24, 25, 88, 89]. The conversion from healthy human intestinal organoids to colorectal progressive tumoroids has been achieved through the introduction of a set of common driver mutations in colorectal cancer via CRISPR-Cas9 gene editing technology, indicating tumor growth as a consequence of cancer driver mutations was independent of SC niche factors and identifying loss of adenomatosis polyposis coli $(A P C)$ and TP53 as pivotal contributors for chromosome instability and aneuploidy [24, 90]. Using organoid models, it was demonstrated that ring finger protein 43 mutations positively regulated Wnt- $\beta$-catenin signaling in human serrated colon adenoma [91], and loss of mutations in caudal type homeobox 2 and $B R A F^{\mathrm{V} 600 \mathrm{E}}$ synergistically drove progression of serrated colorectal cancer [89]. Organoids facilitate better understanding of tumor initiation and progression of cancers at the genetic level.

\section{Organoids in drug development}

During the past decades, numerous anti-cancer drugs developed from screening on conventional 2D culture of large standard cell lines failed in clinical studies [92, 93]. For most cytotoxic agents, broad activity was observed across tumor cell lines, but clinical efficiency noted in patients was in more limited settings [93]. Voskoglou-Nomikos $\mathrm{T}$ evaluated whether in vitro cell lines were reliable in predicting clinical utility. The results showed that in vitro cell line model was predictive for non-small cell lung cancer under the disease-oriented approach, but not for colon cancer [94]. Since cancer organoids are near-physiological architectures, retain specific functions of the parent tumors and can faithfully recapitulate drug responses, the organoid technology fills the gap between drug screening based on classical 2D cell lines and clinical trials. Numerous studies have demonstrated that organoid can serve as an excellent model for evaluating specific responses of cancer patients $[26,69,81,95,96]$. Besides, it also can be an extraordinary alternative to explore the detailed causal epigenetic and genetic alterations underlying drug resistance [97]. Several organoid biobanks of cancers so far have been established for the purposes of identifying and testing novel drugs $[37,38,98]$, and healthy organoids can be utilized to test toxicology.

\section{Drug efficacy testing}

Recently, metastatic gastrointestinal cancer (colorectal cancer and gastroesophageal cancer) organoids derived from patients have been established and employed to identify whether organoids can forecast treatment response among patients. In this study, a wide spectrum of anti-tumor drugs, including used in clinical practice and currently in phases of clinical trials, were enrolled for testing drug sensitivity [26]. The results reflected that organoids cancer faithfully recapitulated treatment responses of gastrointestinal cancers with high sensitivity $(100 \%)$, specificity $(93 \%)$, positive predictive value $(88 \%)$, and negative predictive value $(100 \%)$ in predicting response to chemotherapy in patients [26]. For instance, there was a remarkable association between retinoblastoma 1 amplification and the sensitivity of tumor organoids to cyclin dependent kinase 4/6 inhibitor palbociclib, which was in line with previously published data $[26,99]$. Another example was that patient-derived organoids with $B R A F^{\mathrm{V} 600 \mathrm{E}}$ mutation exhibited dramatically reduced viability but no differences in apoptosis after the exposure of the $B R A F$ inhibitor vemurafenib in comparison with the organoids with no mutations in $B R A F$ gene, which was consistent with the ineffectiveness of monotherapy with $B R A F$ inhibitors in metastatic colorectal cancer [26]. By conducting drug screening on human gastric cancer organoids, Therese Seidlitz and colleagues identified organoids recapitulated the divergent responses to conventional chemotherapeutics, including 5-fluorouracil (5-FU), irinotecan, epirubicin, oxaliplantin, and docetaxel [69]. Furthermore, these organoid lines can be employed to test not only the efficacy of a known mutation-targeted therapy for an individual patient but also the effectiveness of treatment on unknown mutations, as exemplified by trastuzumab treatment for ERBB2 amplifications/ERBB2 mutations and imatinib treatment for an unknown mutation in exon 3 of the KIT receptor [69].

A panel of human colorectal cancer organoids has been assembled for assessing mutation-targeted inhibitors and drug combination therapy, including irreversible epidermal growth factor receptor/Her2 inhibitor afatinib, MEK inhibitor selumetinib, and ERK inhibitor SCH772984 [100]. The results reflected that both the combinations of afatinib plus selumetinib and SCH772984 plus selumetinib significantly inhibited growth of $R A S$-mutant tumor organoids with 
obvious cell cycle block but no impact on cell death. After these drugs were withdrawn, tumor cells could restore proliferation activity, which might hamper the effectiveness of the combination therapy among patients with RAS-mutant colorectal cancer [100]. However, the combination of a preclinical B-cell lymphoma 2 (BCL-2)/BCL-xL inhibitor navitoclax, afatinib, and selumetinib potently promoted cell death in comparison with monotherapy of these drugs, indicating a possible alternative treatment strategy [100].

Huch $\mathrm{M}$, et al. has propagated primary liver tumoroids, which faithfully recapitulated histology, expression patterns and genetic alterations of corresponding original tumors [34]. A total of 29 anti-cancer drugs were enrolled in the proof-of-concept testing of drug sensitivity using organoid model, and the results indicated that these tumoroids facilitated identification of drug sensitivity in individual patient. Intriguingly, it was identified that ERK signaling could be a potential therapeutic target for primary liver cancer patients [34].

A living biobank of primary breast cancer organoids and metastatic breast cancer organoids can also be employed as an excellent platform for drug screening, supported by that responses to afatinib or tamoxifen of organoids showed remarkably similarity to patients [38]. As another example, standard OC cells from patients were cultured to differentiate into organoids [81]. The responses to multiple OC drugs and the association with genomic alterations in organoids were assessed through DeathPro assay for improving drug screening [81]. A diversity of drug responses were observed in OC organoids and drug effects in organoids resembled the findings in clinical trials [81]. For instance, a majority of $\mathrm{OC}$ patients failed to response to paclitaxel, and the addition of paclitaxel to carboplatin did not refine efficacy in comparison to carboplatin monotherapy [81]. Compared with 2D cultures, the responses to drugs of organoids were more similar to the parent tumors. Dasatinib, to which recurrent OC is resistant at clinical phase II, was also ineffective in 3D culture but effective in 2D culture [81].

Because of the extraordinary recapitulation of responses to drugs for original tumors in vivo, prostate cancer organoid lines have also been exploited to help the screening of anti-cancer drugs [37]. For instance, $A R$-amplified prostate cancer organoids were exquisitely sensitive to the AR inhibitor enzalutamide, while $A R$-negative prostate cancer organoids responded to this drug in an opposite manner [37]. Besides, prostate cancer organoid lines harboring both PTEN loss and PIK3R1 mutation were sensitive to everolinus and BKM120 [37].

\section{Pharmacokinetic}

Organoids technology can also be employed in pharmacokinetic testing, which is a pivotal thing during drug development. Human iPSCs-derived intestinal organoids have been generated through appropriate methods with a variety of intestinal cells [101], and these organoids were endowed with pharmacokinetic function [101]. In the condition of some small-molecular compounds, organoids expressed drug transporters, efflux transport activity, and the activation of drug-metabolizing enzyme cytochrome P450 [101]. The results indicated that these organoids could be employed for pharmacokinetic assessment in drug development [101].

\section{Drug toxicity testing}

Another major advantage of organoid technology in drug development is that normal organoids can be generated and exploited for screening of drugs which exclusively target tumor cells without harming healthy cells. Intolerant side effects majorly lead to drug failure in clinical trials, including hepatotoxicity, cardiotoxicity, and nephrotoxicity. Hepatic organoid represents an extraordinary model for hepatotoxicity testing of experimental compounds [102-104]. Drug-related hepatotoxicity is mostly mediated through cytochrome $\mathrm{P} 450$ enzymes, which is inspiringly observed in hepatic organoids at near-physiological levels $[104,105]$. Cardiac adverse effects such as arrhythmias and cardiotoxic effects can also be tested in 3D cultures $[96,106]$. Besides, kidney organoids has also been employed for toxicological research [107].

\section{Immunotherapy}

Immunotherapy, which is among the chief novel and promising strategies, employs the patient's own immune system to kill tumor cells. A prerequisite for immunotherapy is that malignant cells exhibit sufficient immunogenicity to trigger adequate immune response [108, 109]. Mutational status of cancer cells, which contribute to neo-antigens production, is responsible for immune responses $[109,110]$. However, the intensity of immune response induced by neo-antigens of carcinoma is insufficient, which can be addressed through activating and expanding immune cells in vitro for in vivo application in patients.

Multiple studies have brought new hope for the application of organoid technology in immunotherapy, as exemplified by functional maintenance of intraepithelial lymphocytes being co-cultured with mouse intestinal organoids at the presence of interleukin-2 (IL-2), IL7, and IL-15 in the culture medium [111]. Another example is that the short-term maintenance of CD45-positive lymphocytes can be achieved through co-culture with patient-derived organoids of air-liquid interface tumors [112]. Encouragingly, co-cultures of $\mathrm{V}^{2} 2^{+} \mathrm{T}$ lymphocytes and organoids of primary human breast epithelial have been developed successfully, and these $\mathrm{T}$ 
lymphocytes could potently eradicate triple-negative breast cancer cells [113]. These findings signify the possibility that $\mathrm{T}$ lymphocytes from healthy blood donors can be expanded and activated with organoids and subsequently utilized to treat patients, and the possibility that the cytotoxic effects of healthy donor-derived $\mathrm{T}$ cells on patient-derived tumoroids can be tested in vitro.

\section{Personalized medicine}

Personalized medicine, also called precision medicine, aims to identify effective treatment strategies for each patient through better characterization of diseases at molecular and pharmacogenomics levels. As an excellent minute incarnation of an in vivo organ, organoids are superior to conventional models, because this easily established model can better recapitulate in vivo characteristics in phenotype, genotype, and specific functions as well as physiological and pathological changes even after many generations. Organoids are endowed with enormous potential to identify the feasible optimized treatment strategy for the individual patient $[29,30,114,115]$.

Rubin MA and colleagues applied the organoid platform to identify the optimized combination therapy options for some cancer types as exemplified by uterine carcinosarcoma and endometrial adenocarcinoma harboring similar driver mutations in PIK3 catalytic subunit alpha and PTEN [29]. The uterine carcinosarcoma organoid receiving combination treatment of vorinostat and buparlisib showed strongest inhibition in comparison with other combination strategies, while the combination of buparlisib andolaparib was among the most effective strategies for the endometrial adenocarcinoma organoid [29].

Another example was that the KRAS and TP53-mutant organoid of stage IV colorectal cancer only showed notable response to trametinib, and the combination of trametinib and celecoxib was among the chief strongly effective combinational options [29]. Besides, it was also demonstrated that the novel combination of afatinib and histone deacetylase inhibitors contributed to dramatically enhanced growth suppression of colorectal tumoroids with $A P C$ mutations, even greater than the standard FOLFOX (oxaliplatin, FU and leucovorin) regimen did [29]. In addition, drug screening was also conducted on human colorectal organoids from patients, containing many cancer SCs and being resistant to 5-FU and irinotecan [116]. Organoids treated with hedgehog signal inhibitors (AY9944 and GANT61) exhibited reduced cell viability with downregulation of c-Myc, CD44, and Nanog [116], and organoids treated with the combination of AY9944 or GANT61 with 5-FU or irinotecan showed impaired cell viability in comparison to each drug alone [116]. These results reflected that inhibitors of hedgehog signaling could serve as an effective combinational candidate for the treatment of 5-FU or irinotecan-resistant colorectal tumors [116]. Based on the phenomenon that anaplastic lymphoma kinase (ALK) mutation (F1174C) promoted growth and upregulated the expression of neuroendocrine marker neuron-specific enolase in the organoids of prostate small cell carcinoma, alectinic showed more significant effects than crizotinibin terms of inhibiting ALKF1174C-expressing cell expansion [117].

Photodynamic therapy, known as a light-activated cancer therapy, supplements conventional chemotherapies and brings clinical promise for pancreatic cancer treatment [118]. As observed in organoids of metastatic pancreatic carcinoma, intelligent combination of oxaliplatin and neoadjuvant photodynamic therapy exhibited remarkably enhanced anti-tumor efficacy in comparison with any therapy alone, without augment of toxicity [118].

Although it is still in an immature stage of organoid technology in personalized medicine, further efforts can refine this model and broaden horizon in personalized medicine in replacement for conventional "one-size-fits-all" treatments.

\section{Current limitations}

Although organoids have a wide range of potential applications, the current version still represents a somewhat rough model, and researchers still grapple with obstacles of this technology. Firstly, organoids are imperfect reproductions. The "tissues in a dish" comprise only epithelial layer without native microenvironment including surrounding mesenchyme, immune cells, nervous system, or muscular layer [81]. Possible solutions to this limitation are to further refine organotypic culture system or to co-culture with additional cellular elements such as immune cells, stromal cells, or neural cells, as exemplified by iPSC-derived intestinal organoids containing a functional nervous system [119] and co-culture of PDAC organoids with mouse pancreatic stellate cells which differentiated into cancer-related fibroblasts [120]. In spite of these encouraging findings, an immune microenvironment around a tumor is difficult to be modeled. Immune niche of tumors is a complicated system composed of diverse immune cells including cytotoxic lymphocytes, tumor infiltrating dendritic cells, regulatory $\mathrm{T}$ cells, tumor-associated macrophage, and myeloid-derived suppressor cells, and tumor immune microenvironment is in dynamic changes, and there may be differences between different tumor types as well as individual patients. Secondly, fully maturation is an obstacle required to be tackled, which might affect the therapeutic potential. Thirdly, some organoid lines still cannot be expanded for long term, which could be disposed through improvement of culture medium. Fourthly, cancer organoids tend to grow more slowly than 
corresponding organoids from normal epithelial, thus probably contributing to the outgrowth of tumor organoids by contaminating normal epithelial cells. This problem might be addressed through improving the tissue extraction process to minimize the contaminating normal cells. Fifthly, current organoids are majorly derived from epithelium, and further investigation of cultures of nonepithelial organoids is needed, taking the recent advances in establishment of organoids induced from primary glioblastoma as an example. Lastly, the growth factors or small molecular inhibitors in culture medium may have significant effects on gene expression and signaling pathways in organoids, and may affect drug sensitivity. Further efforts are in need for addressing this problem.

\section{Conclusion}

In spite of these limitations, the exciting and promising organoid technology holds enormous potential to more accurately model human tumors. Up to now, highly efficient establishment of organoids has been achieved from both normal and malignant tissues. Using these amazing $3 \mathrm{D}$ cultures, both drug screening and personalized medicine can be prompted dramatically to better predict drug responses and guide optimized therapy strategies for an individual patient. Future efforts will doubtless bring this novel technique closer to clinical practice.

\section{Abbreviations}

2D: Two-dimensional; 3D: Three-dimensional; 5-FU: 5-fluorouracil; ADMEM: Advanced Dulbecco's modified Eagle's medium; ALK: Anaplastic lymphoma kinase; APC: Adenomatosis polyposis coli; AR: Androgen receptor; BCL-2: B-cell lymphoma 2; Cas9: CRISPR-associated protein 9;

CC: Cholangiocarcinoma; CD45: Cluster of differentiation 45; CHC: Combined hepatocellular-cholangiocarcinoma; CNAs: Copy number alterations: CRISPR: Clustered regularly interspersed short palindromic repeats; EBV: Epstein-Barr virus; ECM: Extracellular matrix; EGF: Epidermal growth factor; ESCs: Embryonic stem cells; FBS: Fetal bovine serum; FGF10: Fibroblast growth factor 10; HBSS: Hank's balanced salt solution; HCC: Hepatocellular carcinoma; Her2: Human epidermal growth factor receptor 2;

HGF: Hepatocyte growth factor; IL-2: Interleukin-2; iPSCs: Induced pluripotent stem cells; KRT7: Cytokeratin 7; MDGI: Mammary-derived growth inhibitor; OC: Ovarian cancer; PBS: Phosphate-buffered saline; PDAC: Pancreatic ductal adenocarcinoma; PDTXs: Patient-derived tumor xenografts; PIK3R1: Phosphoinositide-3-kinase regulatory subunit 1; PTEN: Phosphatase and tensin homolog; SCs: Stem cells

\section{Funding}

This work was supported by the National Natural Science Foundation of China (nos. 81572608, 81172422 and 81874120) and supported by Wuhan Science and Technology Bureau (no. 2017060201010170).

\section{Authors' contributions}

$\mathrm{HX}$ performed the selection of literature, drafted the manuscript, and prepared the figures. $\mathrm{XL}, \mathrm{MY}$, and $\mathrm{WZ}$ collected the related references. YS and KW carried out the design of this review and revised the manuscript. All authors contributed to this manuscript. All authors read and approved the final manuscript.

\section{Ethics approval and consent to participate}

Not applicable.

\section{Consent for publication}

Not applicable.

\section{Competing interests}

The authors declare that they have no competing interests.

\section{Publisher's Note}

Springer Nature remains neutral with regard to jurisdictional claims in published maps and institutional affiliations.

\section{Author details}

${ }^{1}$ Department of Oncology, Tongji Hospital of Tongji Medical College, Huazhong University of Science and Technology, 1095 Jiefang Avenue, Wuhan 430030, Hubei, China. ${ }^{2}$ Central Laboratory, the Affiliated Cancer Hospital of Zhengzhou University, Henan Cancer Hospital, Zhengzhou 450000, Henan, China. ${ }^{3}$ Department of Hematology, the Affiliated Cancer Hospital of Zhengzhou University, Henan Cancer Hospital, Zhengzhou 450000, Henan, China.

Received: 2 August 2018 Accepted: 4 September 2018

Published online: 15 September 2018

\section{References}

1. Lai YH, Lin SY, Wu YS, Chen HW, Chen JJW. AC-93253 iodide, a novel SrC inhibitor, suppresses NSCLC progression by modulating multiple Src-related signaling pathways. J Hematol Oncol. 2017;10:172.

2. Lai $Y$, Wei $X$, Lin S, Qin L, Cheng L, Li P. Current status and perspectives of patient-derived xenograft models in cancer research. J Hematol Oncol. 2017;10:106.

3. Meng S, Zhou H, Feng Z, Xu Z, Tang Y, Li P, et al. CircRNA: functions and properties of a novel potential biomarker for cancer. Mol Cancer. 2017;16:94

4. Li A, Zhang T, Zheng M, Liu Y, Chen Z. Exosomal proteins as potential markers of tumor diagnosis. J Hematol Oncol. 2017;10:175.

5. Viardot A, Bargou R. Bispecific antibodies in haematological malignancies. Cancer Treat Rev. 2018;65:87-95.

6. Yu S, Liu Q, Han X, Qin S, Zhao W, Li A, et al. Development and clinical application of anti-HER2 monoclonal and bispecific antibodies for cancer treatment. Exp Hematol Oncol. 2017;6:31.

7. Yu S, Li A, Liu Q, Yuan X, Xu H, Jiao D, et al. Recent advances of bispecific antibodies in solid tumors. J Hematol Oncol. 2017;10:155.

8. Yi M, Jiao D, Xu H, Liu Q, Zhao W, Han X, et al. Biomarkers for predicting efficacy of PD-1/PD-L1 inhibitors. Mol Cancer. 2018;17:129.

9. Wei G, Ding L, Wang J, Hu Y, Huang H. Advances of CD19-directed chimeric antigen receptor-modified $T$ cells in refractory/relapsed acute lymphoblastic leukemia. Exp Hematol Oncol. 2017;6:10.

10. Xu H, Yu S, Liu Q, Yuan X, Mani S, Pestell RG, et al. Recent advances of highly selective CDK4/6 inhibitors in breast cancer. J Hematol Oncol. 2017;10:97.

11. Pang Y, Hou X, Yang C, Liu Y, Jiang G. Advances on chimeric antigen receptor-modified T-cell therapy for oncotherapy. Mol Cancer. 2018;17:91.

12. Liu B, Song Y, Liu D. Recent development in clinical applications of PD-1 and PD-L1 antibodies for cancer immunotherapy. J Hematol Oncol. 2017;10:174.

13. Zhou J, Su J, Fu X, Zheng L, Yin Z. Microfluidic device for primary tumor spheroid isolation. Exp Hematol Oncol. 2017;6:22.

14. Ben-David U, Ha G, Tseng YY, Greenwald NF, Oh C, Shih J, et al. Patientderived xenografts undergo mouse-specific tumor evolution. Nat Genet. 2017:49:1567-75.

15. Byrne AT, Alferez DG, Amant F, Annibali D, Arribas J, Biankin AV, et al. Interrogating open issues in cancer medicine with patient-derived xenografts. Nat Rev Cancer. 2017;17:632.

16. Lancaster MA, Knoblich JA. Organogenesis in a dish: modeling development and disease using organoid technologies. Science. 2014;345:1247125.

17. Drost J, Clevers H. Organoids in cancer research. Nat Rev Cancer. 2018;18: 407-18.

18. Yeung TM, Gandhi SC, Wilding JL, Muschel R, Bodmer WF. Cancer stem cells from colorectal cancer-derived cell lines. Proc Natl Acad Sci U S A. 2010;107: 3722-7.

19. Onuma K, Ochiai M, Orihashi K, Takahashi M, Imai T, Nakagama H, et al. Genetic reconstitution of tumorigenesis in primary intestinal cells. Proc Natl Acad Sci U S A. 2013;110:11127-32.

20. Scanu T, Spaapen RM, Bakker JM, Pratap CB, Wu LE, Hofland I, et al. Salmonella manipulation of host signaling pathways provokes cellular transformation associated with gallbladder carcinoma. Cell Host Microbe. 2015;17:763-74. 
21. Yin $Y$, Bijvelds $M$, Dang $W$, Xu L, van der Eijk AA, Knipping $K$, et al. Modeling rotavirus infection and antiviral therapy using primary intestinal organoids. Antivir Res. 2015;123:120-31.

22. Davies H, Glodzik D, Morganella S, Yates LR, Staaf J, Zou X, et al. HRDetect is a predictor of BRCA1 and BRCA2 deficiency based on mutational signatures. Nat Med. 2017:23:517-25.

23. Drost J, van Boxtel R, Blokzijl F, Mizutani T, Sasaki N, Sasselli V, et al. Use of CRISPRmodified human stem cell organoids to study the origin of mutational signatures in cancer. Science. 2017:358:234-8.

24. Matano M, Date S, Shimokawa M, Takano A, Fujii M, Ohta Y, et al. Modeling colorectal cancer using CRISPR-Cas9-mediated engineering of human intestinal organoids. Nat Med. 2015;21:256-62.

25. Li X, Nadauld L, Ootani A, Corney DC, Pai RK, Gevaert O, et al. Oncogenic transformation of diverse gastrointestinal tissues in primary organoid culture. Nat Med. 2014;20:769-77.

26. Vlachogiannis G, Hedayat S, Vatsiou A, Jamin Y, Fernandez-Mateos J, Khan K, et al. Patient-derived organoids model treatment response of metastatic gastrointestinal cancers. Science. 2018;359:920-6.

27. Sampaziotis F, Justin AW, Tysoe OC, Sawiak S, Godfrey EM, Upponi SS, et al. Reconstruction of the mouse extrahepatic biliary tree using primary human extrahepatic cholangiocyte organoids. Nat Med. 2017;23:954-63.

28. Ramsden CM, Powner MB, Carr AJ, Smart MJ, da Cruz L, Coffey PJ. Stem cells in retinal regeneration: past, present and future. Development. 2013; 140:2576-85.

29. Pauli C, Hopkins BD, Prandi D, Shaw R, Fedrizzi T, Sboner A, et al. Personalized in vitro and in vivo Cancer models to guide precision medicine. Cancer Discov. 2017;7:462-77.

30. Papapetrou EP. Patient-derived induced pluripotent stem cells in cancer research and precision oncology. Nat Med. 2016;22:1392-401.

31. Fujii M, Shimokawa M, Date S, Takano A, Matano M, Nanki K, et al. A colorectal tumor organoid library demonstrates progressive loss of niche factor requirements during tumorigenesis. Cell Stem Cell. 2016;18:827-38.

32. Schutte M, Risch T, Abdavi-Azar N, Boehnke K, Schumacher D, Keil M, et al. Molecular dissection of colorectal cancer in pre-clinical models identifies biomarkers predicting sensitivity to EGFR inhibitors. Nat Commun. 2017:8:14262

33. Weeber F, van de Wetering M, Hoogstraat M, Dijkstra KK, Krijgsman O, Kuilman $T$, et al. Preserved genetic diversity in organoids cultured from biopsies of human colorectal cancer metastases. Proc Natl Acad Sci U S A. 2015;112:13308-11.

34. Broutier L, Mastrogiovanni G, Verstegen MM, Francies HE, Gavarro LM, Bradshaw CR, et al. Human primary liver cancer-derived organoid cultures for disease modeling and drug screening. Nat Med. 2017;23:1424-35.

35. Huang L, Holtzinger A, Jagan I, BeGora M, Lohse I, Ngai N, et al. Ductal pancreatic cancer modeling and drug screening using human pluripotent stem cell- and patient-derived tumor organoids. Nat Med. 2015;21:1364-71.

36. Seino T, Kawasaki S, Shimokawa M, Tamagawa H, Toshimitsu K, Fujii M, et al. Human pancreatic tumor organoids reveal loss of stem cell niche factor dependence during disease progression. Cell Stem Cell. 2018;22:454-67.e6.

37. Gao D, Vela I, Sboner A, laquinta PJ, Karthaus WR, Gopalan A, et al. Organoid cultures derived from patients with advanced prostate cancer. Cell. 2014;159:176-87.

38. Sachs N, de Ligt J, Kopper O, Gogola E, Bounova G, Weeber F, et al. A living biobank of breast Cancer organoids captures disease heterogeneity. Cell. 2018;172:373-86.e10.

39. Evans GS, Flint N, Somers AS, Eyden B, Potten CS. The development of a method for the preparation of rat intestinal epithelial cell primary cultures. J Cell Sci. 1992;101:219-31.

40. Whitehead RH, Demmler K, Rockman SP, Watson NK. Clonogenic growth of epithelial cells from normal colonic mucosa from both mice and humans. Gastroenterology. 1999;117:858-65.

41. Fukamachi H. Proliferation and differentiation of fetal rat intestinal epithelial cells in primary serum-free culture. J Cell Sci. 1992;103:511-9.

42. Perreault N, Beaulieu JF. Use of the dissociating enzyme thermolysin to generate viable human normal intestinal epithelial cell cultures. Exp Cell Res. 1996:224:354-64.

43. Sato T, Vries RG, Snippert HJ, van de Wetering M, Barker $N$, Stange DE, et al. Single Lgr5 stem cells build crypt-villus structures in vitro without a mesenchymal niche. Nature. 2009:459:262-5.

44. Sato $T$, Stange DE, Ferrante M, Vries RG, Van Es JH, Van den Brink S, et al. Long-term expansion of epithelial organoids from human colon, adenoma, adenocarcinoma, and Barrett's epithelium. Gastroenterology. 2011;141:1762-72.

45. Stange DE, Koo BK, Huch M, Sibbel G, Basak O, Lyubimova A, et al. Differentiated troy+ chief cells act as reserve stem cells to generate all lineages of the stomach epithelium. Cell. 2013;155:357-68.

46. Huch M, Dorrell C, Boj SF, van Es JH, Li VS, van de Wetering M, et al. In vitro expansion of single Lgr5+ liver stem cells induced by Wnt-driven regeneration. Nature. 2013;494:247-50.

47. Messner S, Agarkova I, Moritz W, Kelm JM. Multi-cell type human liver microtissues for hepatotoxicity testing. Arch Toxicol. 2013;87:209-13.

48. Binas B, Spitzer E, Zschiesche W, Erdmann B, Kurtz A, Muller T, et al. Hormonal induction of functional differentiation and mammary-derived growth inhibitor expression in cultured mouse mammary gland explants. In Vitro Cell Dev Biol. 1992;28a:625-34

49. Wang M, Liu YE, Ni J, Aygun B, Goldberg ID, Shi YE. Induction of mammary differentiation by mammary-derived growth inhibitor-related gene that interacts with an omega-3 fatty acid on growth inhibition of breast cancer cells. Cancer Res. 2000;60:6482-7.

50. Brock EJ, Ji K, Shah S, Mattingly RR, Sloane BF. In vitro models for studying invasive transitions of ductal carcinoma in situ. J Mammary Gland Biol Neoplasia. 2018. https://doi.org/10.1007/s10911-018-9405-3.

51. Saxen L, Lehtonen E. Embryonic kidney in organ culture. Differentiation. 1987;36:2-11.

52. Avner ED, Piesco NP, Sweeney WE Jr, Ellis D. Renal epithelial development in organotypic culture. Pediatr Nephrol. 1988;2:92-9.

53. van den Berg CW, Ritsma $L$, Avramut MC, Wiersma LE, van den Berg BM, Leuning DG, et al. Renal subcapsular transplantation of PSC-derived kidney organoids induces neo-vasculogenesis and significant glomerular and tubular maturation in vivo. Stem Cell Reports. 2018;10:751-65.

54. Bottenstein JE, Sato GH. Growth of a rat neuroblastoma cell line in serumfree supplemented medium. Proc Natl Acad Sci U S A. 1979;76:514-7.

55. Honegger $P$, Lenoir D, Favrod P. Growth and differentiation of aggregating fetal brain cells in a serum-free defined medium. Nature. 1979;282:305-8.

56. Snyder EY, Kim SU. Hormonal requirements for neuronal survival in culture. Neurosci Lett. 1979;13:225-30.

57. Pasca SP. Building three-dimensional human brain organoids. Nat Neurosci. 2018. https://doi.org/10.1038/s41593-018-0107-3.

58. Qian X, Nguyen HN, Song MM, Hadiono C, Ogden SC, Hammack C, et al. Brain-region-specific organoids using mini-bioreactors for modeling ZIKV exposure. Cell. 2016;165:1238-54.

59. Suga H, Kadoshima T, Minaguchi M, Ohgushi M, Soen M, Nakano T, et al. Self-formation of functional adenohypophysis in three-dimensional culture Nature. 2011:480:57-62.

60. Jo J, Xiao Y, Sun AX, Cukuroglu E, Tran HD, Goke J, et al. Midbrain-like organoids from human pluripotent stem cells contain functional dopaminergic and neuromelanin-producing neurons. Cell Stem Cell. 2016;19:248-57.

61. Muguruma K, Nishiyama A, Kawakami H, Hashimoto K, Sasai Y. Selforganization of polarized cerebellar tissue in 3D culture of human pluripotent stem cells. Cell Rep. 2015:10:537-50.

62. Sakaguchi H, Kadoshima T, Soen M, Narii N, Ishida Y, Ohgushi M, et al Generation of functional hippocampal neurons from self-organizing human embryonic stem cell-derived dorsomedial telencephalic tissue. Nat Commun. 2015:6:8896.

63. Kuo CJ, Curtis C. Organoids reveal cancer dynamics. Nature. 2018;556:441-2.

64. Muthuswamy SK. Organoid models of cancer explode with possibilities. Cell Stem Cell. 2018;22:290-1.

65. Crespo M, Vilar E, Tsai SY, Chang K, Amin S, Srinivasan T, et al. Colonic organoids derived from human induced pluripotent stem cells for modeling colorectal cancer and drug testing. Nat Med. 2017;23:878-84.

66. Boj SF, Hwang Cl, Baker LA, Chio II, Engle DD, Corbo V, et al. Organoid models of human and mouse ductal pancreatic cancer. Cell. 2015;160: 324-38.

67. Lee SH, Hu W, Matulay JT, Silva MV, Owczarek TB, Kim K, et al. Tumor evolution and drug response in patient-derived organoid models of bladder cancer. Cell. 2018;173:515-28.e17.

68. Puca L, Bareja R, Prandi D, Shaw R, Benelli M, Karthaus WR, et al. Patient derived organoids to model rare prostate cancer phenotypes. Nat Commun 2018:9:2404.

69. Seidlitz T, Merker SR, Rothe A, Zakrzewski F, von Neubeck C, Grutzmann K, et al. Human gastric cancer modelling using organoids. Gut. 2018. https:// doi.org/10.1136/gutjnl-2017-314549. 
70. Roper J, Tammela T, Cetinbas NM, Akkad A, Roghanian A, Rickelt S, et al. In vivo genome editing and organoid transplantation models of colorectal cancer and metastasis. Nat Biotechnol. 2017;35:569-76.

71. Cristobal $A$, van den Toorn HWP, van de Wetering $M$, Clevers $H$, Heck AJR, Mohammed S. Personalized proteome profiles of healthy and tumor human colon organoids reveal both individual diversity and basic features of colorectal cancer. Cell Rep. 2017;18:263-74.

72. Nuciforo S, Fofana I, Matter MS, Blumer T, Calabrese D, Boldanova T, et al. Organoid models of human liver cancers derived from tumor needle biopsies. Cell Rep. 2018;24:1363-76.

73. Zhang HC, Kuo CJ. Personalizing pancreatic cancer organoids with hPSCs. Nat Med. 2015;21:1249-51.

74. Walsh AJ, Castellanos JA, Nagathihalli NS, Merchant NB, Skala MC. Optical imaging of drug-induced metabolism changes in murine and human pancreatic cancer organoids reveals heterogeneous drug response. Pancreas. 2016;45:863-9.

75. Ranftl RE, Calvo F. Analysis of breast Cancer cell invasion using an Organotypic culture system. Methods Mol Biol. 2017;1612:199-212.

76. Duarte AA, Gogola E, Sachs N, Barazas M, Annunziato S, de Ruiter JR, et al. BRCA-deficient mouse mammary tumor organoids to study cancer-drug resistance. Nat Methods. 2018:15:134-40.

77. Yoshida T, Sopko NA, Kates M, Liu X, Joice G, McConkey DJ, et al. Three-dimensional organoid culture reveals involvement of Wnt/betacatenin pathway in proliferation of bladder cancer cells. Oncotarget. 2018;9:11060-70.

78. Shenoy TR, Boysen G, Wang MY, Xu QZ, Guo W, Koh FM, et al. CHD1 loss sensitizes prostate cancer to DNA damaging therapy by promoting errorprone double-strand break repair. Ann Oncol. 2017;28:1495-507.

79. Sung SY, Hsieh CL, Law A, Zhau HE, Pathak S, Multani AS, et al. Coevolution of prostate cancer and bone stroma in three-dimensional coculture: implications for cancer growth and metastasis. Cancer Res. 2008;68:9996-10003

80. Saito $Y$, Onishi $N$, Takami H, Seishima R, Inoue $H$, Hirata $Y$, et al. Development of a functional thyroid model based on an organoid culture system. Biochem Biophys Res Commun. 2018;497:783-9.

81. Jabs J, Zickgraf FM, Park J, Wagner S, Jiang X, Jechow K, et al. Screening drug effects in patient-derived cancer cells links organoid responses to genome alterations. Mol Syst Biol. 2017;13:955.

82. da Silva B, Mathew RK, Polson ES, Williams J, Wurdak H. Spontaneous glioblastoma spheroid infiltration of early-stage cerebral organoids models brain tumor invasion. SLAS Discov. 2018;23:862-8.

83. Butler CR, Hynds RE, Gowers KH, Lee Ddo H, Brown JM, Crowley C, et al. Rapid expansion of human epithelial stem cells suitable for airway tissue engineering. Am J Respir Crit Care Med. 2016;194:156-68.

84. Hild M, Jaffe AB. Production of 3-D airway organoids from primary human airway basal cells and their use in high-throughput screening. Curr Protoc Stem Cell Biol. 2016:37:le.9.1-ie.9.15.

85. Chu HW, Rios C, Huang C, Wesolowska-Andersen A, Burchard EG, O'Connor $\mathrm{BP}$, et al. CRISPR-Cas9-mediated gene knockout in primary human airway epithelial cells reveals a proinflammatory role for MUC18. Gene Ther. 2015; 22:822-9.

86. Gao X, Bali AS, Randell SH, Hogan BL. GRHL2 coordinates regeneration of a polarized mucociliary epithelium from basal stem cells. J Cell Biol. 2015;211: 669-82.

87. Roerink SF, Sasaki N, Lee-Six H, Young MD, Alexandrov LB, Behjati S, et al. Intra-tumour diversification in colorectal cancer at the single-cell level. Nature. 2018;556:457-62.

88. Fessler E, Drost J, van Hooff SR, Linnekamp JF, Wang X, Jansen M, et al. TGFbeta signaling directs serrated adenomas to the mesenchymal colorectal cancer subtype. EMBO Mol Med. 2016;8:745-60.

89. Sakamoto N, Feng Y, Stolfi C, Kurosu Y, Green M, Lin J, et al. BRAF(V600E) cooperates with CDX2 inactivation to promote serrated colorectal tumorigenesis. Elife. 2017;6. https://doi.org/10.7554/eLife.20331.

90. Drost J, van Jaarsveld RH, Ponsioen B, Zimberlin C, van Boxtel R, Buijs A, et al. Sequential cancer mutations in cultured human intestinal stem cells. Nature. 2015;521:43-7.

91. Yan HHN, Lai JCW, Ho SL, Leung WK, Law WL, Lee JFY, et al. RNF43 germline and somatic mutation in serrated neoplasia pathway and its association with BRAF mutation. Gut. 2017;66:1645-56.

92. Kamb A. What's wrong with our cancer models? Nat Rev Drug Discov. 2005; $4: 161-5$.
93. Caponigro G, Sellers WR. Advances in the preclinical testing of cancer therapeutic hypotheses. Nat Rev Drug Discov. 2011;10:179-87.

94. Voskoglou-Nomikos T, Pater JL, Seymour L. Clinical predictive value of the in vitro cell line, human xenograft, and mouse allograft preclinical cancer models. Clin Cancer Res. 2003;9:4227-39.

95. Abbasi J. Patient-derived organoids predict cancer treatment response. JAMA. 2018:319:1427.

96. Eder A, Vollert I, Hansen A, Eschenhagen T. Human engineered heart tissue as a model system for drug testing. Adv Drug Deliv Rev. 2016;96:214-24.

97. Duong HQ, Nemazanyy I, Rambow F, Tang SC, Delaunay S, Tharun L, et al. The endosomal protein CEMIP links Wnt signaling to MEK1-ERK1/2 activation in Selumetinib-resistant intestinal organoids. Cancer Res. 2018; 78:4533-48

98. van de Wetering M, Francies HE, Francis JM, Bounova G, lorio F, Pronk A, et al. Prospective derivation of a living organoid biobank of colorectal cancer patients. Cell. 2015;161:933-45.

99. Sherr CJ, Beach D, Shapiro GI. Targeting CDK4 and CDK6: from discovery to therapy. Cancer Discov. 2016;6:353-67.

100. Verissimo CS, Overmeer RM, Ponsioen B, Drost J, Mertens S, VerlaanKlink I, et al. Targeting mutant RAS in patient-derived colorectal cancer organoids by combinatorial drug screening. elife. 2016;5. https://doi.org/ 10.7554/eLife. 18489

101. Onozato D, Yamashita M, Nakanishi A, Akagawa T, Kida Y, Ogawa I, et al. Generation of intestinal organoids suitable for pharmacokinetic studies from human induced pluripotent stem cells. Drug Metab Dispos. 2018. https:// doi.org/10.1124/dmd.118.080374.

102. Kostadinova R, Boess F, Applegate D, Suter L, Weiser T, Singer T, et al. A long-term three dimensional liver co-culture system for improved prediction of clinically relevant drug-induced hepatotoxicity. Toxicol Appl Pharmacol. 2013;268:1-16.

103. Meng Q. Three-dimensional culture of hepatocytes for prediction of druginduced hepatotoxicity. Expert Opin Drug Metab Toxicol. 2010;6:733-46.

104. Katsuda T, Kawamata M, Hagiwara K, Takahashi RU, Yamamoto Y, Camargo FD, et al. Conversion of terminally committed hepatocytes to culturable bipotent progenitor cells with regenerative capacity. Cell Stem Cell. 2017;20: 41-55.

105. Huch M, Gehart H, van Boxtel R, Hamer K, Blokzijl F, Verstegen MM, et al. Long-term culture of genome-stable bipotent stem cells from adult human liver. Cell. 2015;160:299-312.

106. Voges HK, Mills RJ, Elliott DA, Parton RG, Porrello ER, Hudson JE Development of a human cardiac organoid injury model reveals innate regenerative potential. Development. 2017;144:1118-27.

107. Takasato M, Er PX, Chiu HS, Maier B, Baillie GJ, Ferguson C, et al. Kidney organoids from human iPS cells contain multiple lineages and model human nephrogenesis. Nature. 2015;526:564-8.

108. Sato T, Clevers H. SnapShot: growing organoids from stem cells. Cell. 2015; 161:1700-.e1.

109. Rizvi NA, Hellmann MD, Snyder A, Kvistborg P, Makarov V, Havel JJ, et al. Cancer immunology. Mutational landscape determines sensitivity to PD-1 blockade in non-small cell lung cancer. Science. 2015;348:124-8.

110. Asaoka Y, ljichi H, Koike K. PD-1 blockade in tumors with mismatch-repair deficiency. N Engl J Med. 2015;373:1979.

111. Nozaki K, Mochizuki W, Matsumoto Y, Matsumoto T, Fukuda M, Mizutani T, et al. Co-culture with intestinal epithelial organoids allows efficient expansion and motility analysis of intraepithelial lymphocytes. J Gastroenterol. 2016;51:206-13.

112. Finnberg NK, Gokare P, Lev A, Grivennikov SI, AWt MF, Campbell KS, et al. Application of 3D tumoroid systems to define immune and cytotoxic therapeutic responses based on tumoroid and tissue slice culture molecular signatures. Oncotarget. 2017;8:66747-57.

113. Zumwalde NA, Haag JD, Sharma D, Mirrielees JA, Wilke LG, Gould MN, et al. Analysis of immune cells from human mammary ductal epithelial organoids reveals Vdelta2 $+T$ cells that efficiently target breast carcinoma cells in the presence of bisphosphonate. Cancer Prev Res (Phila). 2016;9:305-16.

114. Tiriac H, Bucobo JC, Tzimas D, Grewel S, Lacomb JF, Rowehl LM, et al. Successful creation of pancreatic cancer organoids by means of EUS-guided fine-needle biopsy sampling for personalized cancer treatment. Gastrointest Endosc. 2018;87:1474-80.

115. Organoids May Point to Best Therapy. Cancer Discov. 2018;8:524.

116. Usui T, Sakurai M, Umata K, Elbadawy M, Ohama T, Yamawaki H, et al. Hedgehog signals mediate anti-cancer drug resistance in three-dimensional 
primary colorectal cancer organoid culture. Int J Mol Sci. 2018;19(4). https:// doi.org/10.3390/ijms19041098.

117. Carneiro BA, Pamarthy S, Shah AN, Sagar V, Unno K, Han H, et al. Anaplastic lymphoma kinase mutation (ALK F1174C) in small cell carcinoma of the prostate and molecular response to alectinib. Clin Cancer Res. 2018;24:2732-9.

118. Broekgaarden M, Rizvi I, Bulin AL, Petrovic L, Goldschmidt R, Massodi I, et al. Neoadjuvant photodynamic therapy augments immediate and prolonged oxaliplatin efficacy in metastatic pancreatic cancer organoids. Oncotarget. 2018;9:13009-22.

119. Workman MJ, Mahe MM, Trisno S, Poling HM, Watson CL, Sundaram N, et al. Engineered human pluripotent-stem-cell-derived intestinal tissues with a functional enteric nervous system. Nat Med. 2017;23:49-59.

120. Ohlund D, Handly-Santana A, Biffi G, Elyada E, Almeida AS, Ponz-Sarvise M, et al. Distinct populations of inflammatory fibroblasts and myofibroblasts in pancreatic cancer. J Exp Med. 2017;214:579-96.

Ready to submit your research? Choose BMC and benefit from:

- fast, convenient online submission

- thorough peer review by experienced researchers in your field

- rapid publication on acceptance

- support for research data, including large and complex data types

- gold Open Access which fosters wider collaboration and increased citations

- maximum visibility for your research: over $100 \mathrm{M}$ website views per year

At $\mathrm{BMC}$, research is always in progress.

Learn more biomedcentral.com/submissions 